\title{
Eosinophils generate brominating oxidants in allergen-induced asthma
}

\author{
Weijia Wu, ${ }^{1,2}$ Michael K. Samoszuk, ${ }^{3}$ Suzy A.A. Comhair, ${ }^{4}$ Mary Jane Thomassen, ${ }^{5}$ \\ Carol F. Farver, ${ }^{6}$ Raed A. Dweik, ${ }^{5}$ Mani S. Kavuru, ${ }^{5}$ Serpil C. Erzurum, ${ }^{4,5}$ and \\ Stanley L. Hazen ${ }^{1,2,7}$ \\ ${ }^{1}$ Department of Cell Biology, Cleveland Clinic Foundation, Cleveland, Ohio, USA \\ ${ }^{2}$ Chemistry Department, Cleveland State University, Cleveland, Ohio, USA \\ ${ }^{3}$ Quest Diagnostics Inc., San Juan Capistrano, California, USA \\ ${ }^{4}$ Department of Cancer Biology, \\ ${ }^{5}$ Department of Pulmonary and Critical Care Medicine, \\ ${ }^{6}$ Department of Anatomic Pathology, and \\ ${ }^{7}$ Department of Cardiology, Cleveland Clinic Foundation, Cleveland, Ohio, USA \\ Address correspondence to: Stanley L. Hazen, Cleveland Clinic Foundation, Lerner Research Institute, \\ Department of Cell Biology, 9500 Euclid Avenue, NC-10, Cleveland, Ohio 44195, USA. Phone: (216) 445-9763; \\ Fax: (216) 444-9404; E-mail: hazens@ccf.org; URL: http://www.lerner.ccf.org/ri/pi/hazens.html.
}

Received for publication February 24, 2000, and accepted in revised form March 27, 2000.

\begin{abstract}
Eosinophils promote tissue injury and contribute to the pathogenesis of allergen-triggered diseases like asthma, but the chemical basis of damage to eosinophil targets is unknown. We now demonstrate that eosinophil activation in vivo results in oxidative damage of proteins through bromination of tyrosine residues, a heretofore unrecognized pathway for covalent modification of biologic targets in human tissues. Mass spectrometric studies demonstrated that 3 -bromotyrosine serves as a specific "molecular fingerprint" for proteins modified through the eosinophil peroxidase- $\mathrm{H}_{2} \mathrm{O}_{2}$ system in the presence of plasma levels of halides. We applied a localized allergen challenge to model the effects of eosinophils and brominating oxidants in human lung injury. Endobronchial biopsy specimens from allergen-challenged lung segments of asthmatic, but not healthy control, subjects demonstrated significant enrichments in eosinophils and eosinophil peroxidase. Baseline levels of 3-bromotyrosine in bronchoalveolar lavage (BAL) proteins from mildly allergic asthmatic individuals were modestly but not statistically significantly elevated over those in control subjects. After exposure to segmental allergen challenge, lung segments of asthmatics, but not healthy control subjects, exhibited a >10-fold increase in BAL 3-bromotyrosine content, but only two- to threefold increases in 3chlorotyrosine, a specific oxidation product formed by neutrophil- and monocyte-derived myeloperoxidase. These results identify reactive brominating species produced by eosinophils as a distinct class of oxidants formed in vivo. They also reveal eosinophil peroxidase as a potential therapeutic target for allergen-triggered inflammatory tissue injury in humans.
\end{abstract}

J. Clin. Invest. 105:1455-1463 (2000).

\section{Introduction}

Eosinophils are a specialized form of white blood cells that play a unique role in host defense mechanisms. In contrast to neutrophils, which primarily ingest and kill relatively small microbes within the harsh environs of a phagolysosomal compartment, eosinophils are recruited to destroy helminthic parasites and other large invading metazoan pathogens. The biochemical mechanisms used by eosinophils in vivo to perform their functions are not known. In vitro studies have focused on their capacity to generate inflammatory mediators, release cytotoxic granule constituents, and generate free radicals and reactive oxidant species (1-6). The reactive species they form, however, also have the potential to harm host tissue and cause tissue injury. Allergic inflammatory diseases such as chronic asthma are characterized by eosinophil recruitment and activation (5-7). Although eosinophils are widely believed to play a central role in promoting inflammatory injury in asthma, the biochemical pathways used by these phagocytes to damage biologic targets in vivo have not yet been established.

Activation of eosinophils in vitro by a variety of stimuli often triggers a respiratory burst in which superoxide $\left(\mathrm{O}_{2}{ }^{-}\right)$and hydrogen peroxide $\left(\mathrm{H}_{2} \mathrm{O}_{2}\right)$ are formed and granule contents are secreted into the extracellular milieu (1). The respiratory burst of eosinophils generates several times as much $\mathrm{O}_{2}{ }^{-}$and $\mathrm{H}_{2} \mathrm{O}_{2}$ as a corresponding number of neutrophils (8-10). Eosinophil peroxidase (EPO), a highly cationic heme protein secreted by activated eosinophils, is believed to play an instrumental role in mediating both the destruction of invading parasites and pathogens and the pathological damage of host tissues $(1-6,11-16)$. EPO is one of the most abundant proteins in eosinophils $\left(15 \mu \mathrm{g} / 10^{6}\right.$ eosinophils), comprising approximately $25 \%$ of the total 
protein mass of specific granule protein (17). A structurally and functionally distinct enzyme from neutrophil myeloperoxidase (MPO) (17-19), it shares with MPO the unique ability to use halides or pseudohalides $\left(\mathrm{X}^{-}\right)$and $\mathrm{H}_{2} \mathrm{O}_{2}$ derived from the respiratory burst to generate cytotoxic hypohalous acids (HOX): $\mathrm{H}_{2} \mathrm{O}_{2}+\mathrm{X}^{-}+\mathrm{H}^{+}$ $\rightarrow \mathrm{HOX}+\mathrm{H}_{2} \mathrm{O}$; where $\mathrm{X}=\mathrm{Cl}^{-}, \mathrm{Br}^{-}, \mathrm{I}^{-}$, or $\left.\mathrm{SCN}^{-}\right)$. In cellfree models, halogenating oxidants formed by the EPO$\mathrm{H}_{2} \mathrm{O}_{2}-\mathrm{X}^{-}$system are effective cytotoxins for multiple targets such as multicellular worms or parasites, bacteria, viruses, and host cells $(1,11-16,20)$.

Nearly two decades ago, Weiss and colleagues first suggested a potential role for bromide $\left(\mathrm{Br}^{-}\right)$in mammalian systems (2). Eosinophils were shown to use bromide instead of chloride to generate a halogenating oxidant despite a greater than 1,000-fold excess of chloride. In contrast, neutrophils selectively use chloride $\left(\mathrm{Cl}^{-}\right)$at plasma levels of halides to generate chlorinating oxidants (21-23). Studies using chemical trapping agents demonstrated that at least $25 \%$ of the oxygen consumed by isolated human eosinophils stimulated in media possessing plasma levels of bromide and chloride could be accounted for by the generation of brominating species (3). However, a role for bromide as a physiological substrate of EPO in vivo has been questioned since the discovery that the peroxidase preferentially uses the pseudohalide thiocyanate $\left(\mathrm{SCN}^{-}\right)(24)$, an abundant anion in plasma and interstitial fluids, at concentrations of halides normally found in plasma and extracellular fluids $\left(100 \mathrm{mM} \mathrm{Cl}^{-}, 20-150 \mu \mathrm{M} \mathrm{Br}^{-}\right.$, 0.1-0.6 $\mu \mathrm{M} \mathrm{I}^{-}$, and 0-70 $\mu \mathrm{M} \mathrm{SCN}^{-}$; ref. 25).

Direct chemical evidence of how eosinophils participate in tissue damage in vivo is lacking. We hypothesized that brominated products might serve as a powerful tool to identify sites of eosinophil-mediated oxidative damage in vivo. We now demonstrate that eosinophil activation in vitro and in vivo results in oxidative damage of proteins through bromination of tyrosine residues, a heretofore unrecognized pathway for covalent modification of biologic targets in human health or disease.

\section{Methods}

Eosinophil and neutrophil isolation. Neutrophils were isolated by buoyant density centrifugation as described previously (26). Low levels of contaminating eosinophils were then removed by fluorescence activated cell sorting (27). Eosinophils were isolated from whole blood obtained from normal healthy volunteers using CD16 microbeads (Miltenyi Biotec, Auburn, California, USA), as described elsewhere (28). Neutrophil and eosinophil preparations were shown cytologically to be at least $99 \%$ pure. In addition, SDS-PAGE with in-gel tetramethylbenzidine peroxidase staining (29) was performed on detergent extracts of eosinophil and neutrophil preparations to confirm that no detectable cross contamination of leukocyte peroxidase activity was observed.

Cell experiments. Studies with activated leukocytes were performed at $37^{\circ} \mathrm{C}$ in Hanks' balanced salt solution ( $\mathrm{pH}$ 7.2; magnesium-, calcium-, phenol red- and bicarbonate-free; GIBCO BRL, Gaithersburg, Maryland, USA) supplemented with $100 \mu \mathrm{M}$ diethylenetriaminepentaacetic acid (DTPA). Studies using inductively coupled plasma mass spectrometry confirmed that the contaminating level of $\mathrm{Br}^{-}$is this media was approximately $6-8 \mu \mathrm{M}$ (sum of ${ }^{79} \mathrm{Br}$ and ${ }^{81} \mathrm{Br}$ isotopomers). Cells $\left(1 \times 10^{6} / \mathrm{mL}\right)$ were incubated with BSA $(1 \mathrm{mg} / \mathrm{mL})$ and the indicated additional concentrations of NaBr. Cells were activated by addition of PMA (200 $\mathrm{nM})$. Superoxide generation by activated human eosinophils was measured as the superoxide dismutaseinhibitable reduction of ferricytochrome c (30).

Sample preparation and mass spectrometry. The 3chlorotyrosine content of proteins in bronchoalveolar lavage (BAL) was determined by stable isotope dilution gas chromatography/mass spectrometry (GC/MS) (31). 3-Chloro $\left[{ }^{13} \mathrm{C}_{6}\right]$ tyrosine standard was prepared and isolated following exposure of $\left.\mathrm{L}^{[13} \mathrm{C}_{6}\right]$ tyrosine to $\mathrm{HOCl}(1: 1, \mathrm{~mol} / \mathrm{mol})$ in $20 \mathrm{mM}$ phosphoric acid (32). 3-Bromo $\left[{ }^{13} \mathrm{C}_{6}\right]$ tyrosine and 3,5-dibromo $\left[{ }^{13} \mathrm{C}_{6}\right]$ tyrosine standards for analyses were similarly synthesized by exposure of $\mathrm{L}-\left[{ }^{13} \mathrm{C}_{6}\right]$ tyrosine to $\mathrm{HOBr}(1: 1, \mathrm{~mol} / \mathrm{mol})$, and then isolated by preparative reverse-phase HPLC (33). The content of 3-bromotyrosine, 3,5-dibromotyrosine, and tyrosine in reaction mixtures and BAL samples were determined by GC/MS (33). Briefly, proteins were first precipitated and desalted twice (to remove residual $\mathrm{Cl}^{-}$and $\mathrm{Br}^{-}$) with a single-phase extraction mixture composed of $\mathrm{H}_{2} \mathrm{O}$ :methanol: $\mathrm{H}_{2} \mathrm{O}$-saturated diethyl ether (1:3:7, vol/vol/vol). Samples were supplemented with $50 \mathrm{pmol}$ of each internal standard, and then proteins were hydrolyzed in $4 \mathrm{~N}$ methane sulfonic acid $(0.5 \mathrm{~mL})$ supplemented with $1 \%$ phenol for 24 hours at $110^{\circ} \mathrm{C}$ under an argon atmosphere. Protein hydrolysates were adjusted to $2 \mathrm{ml}$ volume with $0.1 \%$ trifluoroacetic acid (TFA) and passed over a mini solidphase C18 extraction column (Supelclean LC-18 SPE tubes; 3 mL; Supelco Inc., Bellefonte, Pennsylvania, USA) equilibrated with $0.1 \%$ TFA. Columns were washed with $2 \mathrm{~mL} 0.1 \%$ TFA and amino acids were eluted with $2 \mathrm{~mL} \mathrm{H}_{2} \mathrm{O}$ :methanol (1:1, vol/vol) supplemented with $0.1 \%$ TFA. The amino acid solution was dried under vacuum and immediately derivatized. GC/MS analyses of L-tyrosine oxidation products were performed after derivatization to their $n$-propyl per heptafluorylbutyryl or $n$-propyl per pentafluorylproprionyl derivatives (34) on a Finnigan Voyager GC/MS in the negative ion-chemical ionization mode. Results are normalized to the content of the precursor amino acid, L-tyrosine, which was similarly quantified by GC/MS (31) except for using $\left.\mathrm{L}^{13} \mathrm{C}_{9}{ }^{15} \mathrm{~N}\right]$ tyrosine as internal standard. In all studies, intrapreparative formation of 3-bromo $\left[{ }^{13} \mathrm{C}_{9}{ }^{15} \mathrm{~N}\right]$ tyrosine, 3,5-dibro$\mathrm{mo}\left[{ }^{13} \mathrm{C}_{9}{ }^{15} \mathrm{~N}\right]$ tyrosine, or 3 -chloro $\left[{ }^{13} \mathrm{C}_{9}{ }^{15} \mathrm{~N}\right]$ tyrosine was negligible (i.e., $<5 \%$ of the level of the natural abundance product observed).

Subjects. BAL specimens examined in this study were obtained as part of a separate clinical investigation that was described recently (35). Eight asthmatic and six 
healthy control subjects were enrolled. Because the amount of lavage obtained from some subjects was limiting, not all measures could be performed on every sample. The number of samples evaluated for each parameter is stated in figure and table legends. To be enrolled, asthmatic individuals had to have shown greater than or equal to both a $200-\mathrm{mL}$ increase and a $12 \%$ increase in absolute forced expiratory volume in 1 second $\left(\mathrm{FEV}_{1}\right)$ either spontaneously or after bronchodilator within the year before enrollment, tested positive on an allergy prick skin test for multiple aeroallergens, and have satisfied the definition of asthma as defined by the National Institutes of Health guidelines (36). Asthma severity and temporal course in volunteers included mild intermittent and mild persistent asthma (36). Asthmatic individuals had not received oral or intravenous corticosteroids within the past 6 months. All asthmatic individuals used shortacting inhaled $\beta 2$-agonists on an as-needed basis, but did not use $\beta 2$-agonist medication on the day of bronchoscopic study. Healthy controls were nonsmokers and had a negative skin test and a negative methacholine challenge test.

Segmental allergen challenge model. Allergic asthmatics first underwent whole lung allergen challenge in which escalating doses of antigen were given to demonstrate antigen responsiveness and to determine the provocative dose that caused a $20 \%$ reduction in $\mathrm{FEV}_{1}$ (35). After at least a 4-week "cool off" period, $10 \%$ of this dose was then diluted into $10 \mathrm{~mL}$ normal saline and used for segmental allergen challenge via fiberoptic bronchoscopy (see later here). Healthy nonallergic controls were challenged with 100 protein nitrogen units (PNUs) of either ragweed or grass allergen (Greer Laboratories, Lenoir, North Carolina, USA). The average age, baseline $\mathrm{FEV}_{1}$ (\% predicted), and percent fall in $\mathrm{FEV}_{1}$ at maximum antigen dose during whole lung antigen challenge in BAL 48 hours after allergen challenge in asthmatic versus control subjects were as follows: $36.6 \pm 6.7$ vs. $42.5 \pm 8.6$ years old; $86.6 \pm 15.1 \%$ vs. $98.7 \pm 14.3 \%$; and $-26.6 \pm 6.9 \%$ vs. 0.3 $\pm 4.6 \%$, respectively (35).

Healthy control and allergic asthmatic subjects underwent fiberoptic bronchoscopy, and a specific segment in the left lung (lingula, superior subsegment) was lavaged with normal saline to obtain a baseline sample ( $\mathrm{t}=0$ hours). Normal saline $(10 \mathrm{~mL})$ was then instilled into an adjacent subsegment (lingula, inferior subsegment) as a control "normal saline challenge." Specific segments in the contralateral lung (right middle lobe, medial and lateral subsegments) were then each exposed to a known allergen $(\mathrm{Ag})$ in 10 $\mathrm{mL}$ normal saline. The medial subsegment of the right middle lobe was lavaged 10 minutes later with normal saline (10 minutes) to assess the immediate effect of allergen challenge. Forty-eight hours later, fiberoptic bronchoscopy was repeated and both allergen-challenged (right middle lobe, lateral subsegment) and normal saline-challenged (lingula, inferior subsegment) lung segments were lavaged with normal saline.
Immediately after BAL was recovered, cells were removed by centrifugation and the supernatant stored in the presence of antioxidants and peroxidase inhibitors at $-70^{\circ} \mathrm{C}(100 \mu \mathrm{M}$ DTPA [pH 7.0], $100 \mu \mathrm{M}$ butylated hydroxytoluene added from a $100 \times$ ethanolic stock, and $10 \mathrm{mM} 3$-aminotriazole) (37) until analysis. To calculate epithelial lining fluid (ELF) volume, the concentration of urea in paired blood and BAL samples were determined using a blood urea nitrogen assay (Sigma Diagnostics, St. Louis, Missouri, USA). The study was approved by the Cleveland Clinic Foundation Institutional Review Board, and subjects gave written informed consent.

Analysis of endobronchial biopsy specimens. Endobronchial biopsy specimens were obtained 48 hours after antigen (and normal saline) challenge. Specific autofluorescence imaging of eosinophil peroxidase in endobronchial biopsies was performed as described elsewhere (38-40). EPO-specific in situ peroxidase staining of tissues was performed after treatment of slides with $0.01 \mathrm{M} \mathrm{KCN}$ to inhibit MPO $(41,42)$.

Statistics. Data represent the mean \pm SD of the indicated number of samples. Statistical analyses were made using a paired two-tailed Student's $t$ test. For all hypotheses, the significance level was 0.05 . When multiple comparisons were made, a Bonferroni correction to the significance criterion for each test was made.

\section{Results}

Eosinophils brominate protein tyrosine residues. Structural identification of stable oxidation products formed by the action of activated eosinophils on target proteins is lacking. Recently, we identified 3-bromotyrosine and 3,5dibromotyrosine as products formed on proteins exposed to either chemical brominating agents (e.g., $\mathrm{HOBr}, N$-bromo amines, and $N, N$-dibromo amines) or a cell-free system composed of isolated EPO and the cosubstrates $\mathrm{H}_{2} \mathrm{O}_{2}$ and $\mathrm{Br}^{-}(33)$. We therefore first investigated whether protein tyrosine residues served as endogenous targets for covalent modification by eosinophils activated in media supplemented with physiological concentrations of serum albumin and halides $\left(\mathrm{Cl}^{-}\right.$and $\left.\mathrm{Br}^{-}\right)$. GC-MS analysis demonstrated that eosinophils readily modified protein tyrosine residues forming both brominated products, 3-bromotyrosine and 3,5-dibromotyrosine (Figure 1). Product identity was confirmed by demonstrating the anticipated mass spectrometry of the derivatized brominated amino acids (Figure 1, $c$ and d). The time course of eosinophil-mediated tyrosine bromination paralleled the rate of superoxide $\left(\mathrm{O}_{2}{ }^{\bullet-}\right)$ production by the phagocytes during a respiratory burst (Figure 1a). Furthermore, formation of protein-bound 3-bromotyrosine demonstrated an absolute requirement for cell activation and $\mathrm{Br}^{-}$and was inhibited by the $\mathrm{H}_{2} \mathrm{O}_{2}$ scavenger catalase and EPO inhibitors such as azide and aminotriazole (Figure 1b). These results are consistent with eosinophils using the EPO- $\mathrm{H}_{2} \mathrm{O}_{2}-\mathrm{Br}^{-}$system to brominate protein tyrosine residues at plasma levels of halides. 
3-Bromotyrosine serves as a "molecular fingerprint" for eosinophil-dependent oxidative damage of proteins. To examine the selectivity of 3-bromotyrosine as a marker for protein damage by eosinophils, the capacity of isolated leukocytes (eosinophils and neutrophils) to generate 3-bromotyrosine and 3-chlorotyrosine, a specific marker for MPO-catalyzed protein oxidation (32), was determined. Eosinophils readily formed protein-bound 3-bromotyrosine at plasma levels of $\mathrm{Cl}^{-}$ and $\mathrm{Br}^{-}$, whereas little 3-chlorotyrosine was formed (Figure 2a). In contrast, neutrophils formed 3chlorotyrosine, but failed to generate significant levels of 3-bromotyrosine across the physiological range of $\mathrm{Br}^{-}$concentrations (Figure $2 \mathrm{~b}$ ). These results suggest that 3-bromotyrosine and 3-chlorotyrosine may serve as selective "molecular fingerprints" to identify sites of tissue injury by the leukocyte peroxidases EPO and MPO, respectively.

Brominating oxidants are formed in allergen-induced asthma. To evaluate whether brominating oxidants play a role in promoting oxidative damage in vivo, we used a provocative model for human asthma exacerbation that elicits a dramatic eosinophilic response, segmental allergen challenge (43-46). In this model, human subjects (healthy control and allergic asthmatic) undergo fiberoptic bronchoscopy, and a spe- a

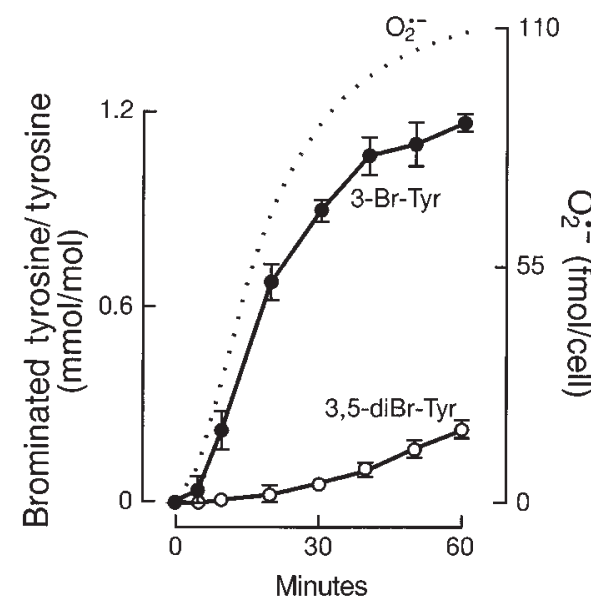

C

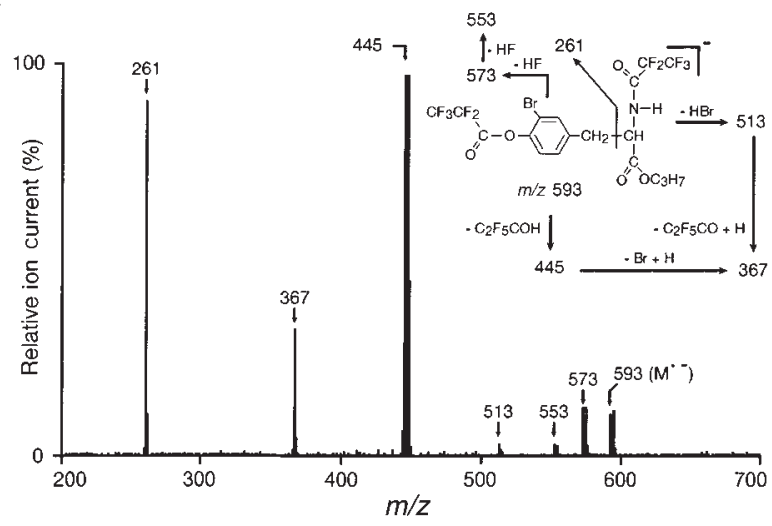

b

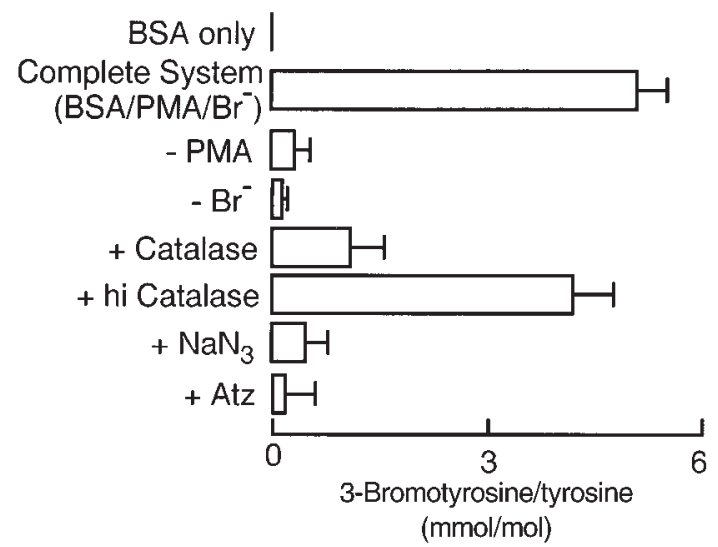

d

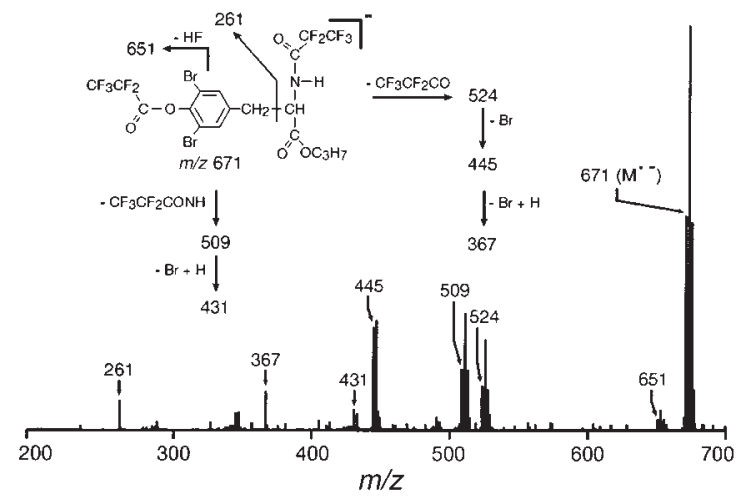

Figure 1

Activated eosinophils utilize plasma levels of bromide to covalently modify protein tyrosine residues. (a) Human eosinophils $\left(1 \times 10^{6} / \mathrm{mL}\right)$ were incubated at $37^{\circ} \mathrm{C}$ in Hanks' balanced salt solution supplemented with DTPA (100 $\left.\mu \mathrm{M}\right), \mathrm{BSA}, 1 \mathrm{mg} / \mathrm{mL}$, and bromide (100 $\mu \mathrm{M} \mathrm{NaBr}$ ). Eosinophils were activated with PMA (200 nM) and maintained in suspensions by intermittent inversion (Complete System). At the indicated times, eosinophils were removed by centrifugation. Supernatants were delipidated, desalted, and hydrolyzed, and the content of protein-bound 3-bromotyrosine and 3,5-dibromotyrosine was determined by stable isotope dilution GC-MS analysis. In a parallel set of experiments, superoxide production (in the absence of bromide and BSA) was determined as the superoxide dismutase-inhibitable reduction of ferricytochrome c. Data represent the mean \pm SD of triplicate determinations (3-bromotyrosine and 3,5-dibromotyrosine) or a representative time course of $\mathrm{O}_{2}{ }^{--}$production from an experiment performed at least four times. (b) The content of 3-bromotyrosine generated on target proteins after 2-hour incubation in the Complete System was determined by stable isotope dilution GC-MS analysis. Additions or deletions to the Complete System were as indicated. The final concentrations of additions were: catalase and heat inactivated catalase (hi Catalase), $10 \mu \mathrm{g} / \mathrm{mL} ; \mathrm{NaN}_{3}, 1 \mathrm{mM} ; 3$-aminotriazole (Atz), $10 \mathrm{mM}$. Values are the mean $\pm \mathrm{SD}$ of triplicate determinations. (c and d) Electron capture negative ion chemical ionization mass spectrum of $n$-propyl, per pentafluoroproprionyl derivatized (c) 3-bromotyrosine and (d) 3,5-dibromotyrosine recovered in amino acid hydrolysates of BSA exposed to activated eosinophils. (Insets) structures and proposed fragmentation pathways for derivatized (c) 3-bromotyrosine and (d) 3,5-dibromotyrosine. 


\section{Figure 2}

Specificity of 3-bromotyrosine and 3-chlorotyrosine formation on proteins exposed to activated human eosinophils and neutrophils. Human eosinophils and neutrophils $\left(1 \times 10^{6} / \mathrm{mL}\right)$ were individually incubated for 2 hours at $37^{\circ} \mathrm{C}$ in Hanks' balanced salt solution supplemented with DTPA $(100 \mu \mathrm{M})$, BSA $(1 \mathrm{mg} / \mathrm{mL})$, and the indicated concentrations of bromide $(0-100 \mu \mathrm{M} \mathrm{NaBr})$. Leukocytes were activated with PMA (200 nM) and maintained in suspensions by intermittent inversion. The content of protein-bound 3-bromotyrosine and 3-chlorotyrosine was then determined by stable isotope dilution GC-MS analysis. Data represent the mean \pm SD of triplicate determinations.

cific segment of one lung is challenged by administration of a predetermined allergen at a known dose and for a set time interval. A lung segment in the contralateral lung is similarly challenged with normal saline. Forty-eight hours later, fiberoptic bronchoscopy is repeated and both allergen- and normal saline-challenged lung segments are lavaged with normal saline and biopsied. Specimens examined in this study were obtained as part of a clinical investigation that was described recently (35). Control and allergic asthmatic (non-steroid-dependent) subjects were age- and sex-matched, nonsmokers, and demonstrated similar BAL cell counts and differentials at baseline (Table 1). After allergen challenge, but not normal saline challenge, a robust infiltration of eosinophils in allergic asthmatic subjects was revealed by histological examination of endobronchial biopsy specimens (Figure 3, a and b) and cytological examination of BAL fluids (Table 1). In contrast, examination of endobronchial biopsies and BAL from healthy control (nonasthmatic) subjects demonstrated no significant eosinophilia ( $\leq$ one eosinophil per high power field) and negligible $(<0.5 \%)$ levels of eosinophils, respectively, after both allergen and normal saline challenge (data not shown).
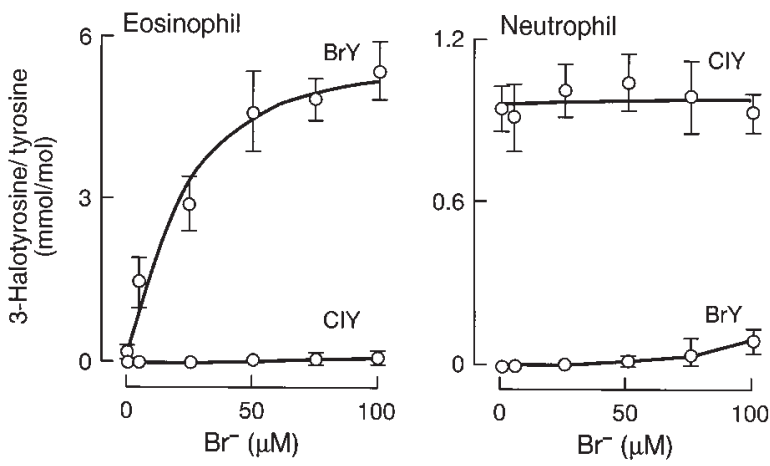

To determine whether EPO is enriched in airways of allergen-challenged, but not normal saline-challenged, allergic asthmatic subjects, several studies were performed. First, endobronchial biopsy specimens were examined by fluorescence microscopy using excitation and emission wavelengths specific for the autofluorescence of the porphyrin group of EPO (38-40). Dramatic increases in fluorescence intensity were observed in allergen-challenged, but not normal saline-challenged, specimens from allergic asthmatic subjects (Figure 3, $\mathrm{c}$ and d). Endobronchial biopsy specimens were also examined by staining for in situ peroxidase activity under conditions specific for EPO activity (41, 42). Staining was intense only in biopsies recovered from allergen-challenged lung segments (48 hours) of allergic asthmatic subjects and colocalized with eosinophils (data not shown).

Eosinophil infiltration into the airways of asthmatic subjects after provocation with allergen does not indicate whether the phagocytes are active and promote oxidative damage of proteins in vivo. To test whether EPO-generated brominating oxidants are formed in response to allergen-triggered eosinophil recruitment to asthmatic airways, the content of 3bromotyrosine in proteins present in BAL (after

Table 1

\begin{tabular}{|c|c|c|c|c|c|c|}
\hline & \multicolumn{3}{|c|}{ Nonasthmatics } & \multicolumn{3}{|c|}{ Asthmatics } \\
\hline & $\begin{array}{c}\text { Baseline } \\
\text { Control } \\
(5)\end{array}$ & $\begin{array}{c}10 \text { minutes } \\
\text { Challenge } \\
(5)\end{array}$ & $\begin{array}{l}48 \text { hours } \\
\text { Challenge } \\
(6)\end{array}$ & $\begin{array}{l}\text { Baseline } \\
\text { Control } \\
\text { (7) }\end{array}$ & $\begin{array}{l}10 \text { minutes } \\
\text { Challenge } \\
(7)\end{array}$ & $\begin{array}{c}48 \text { hours } \\
\text { Challenge } \\
\text { (7) }\end{array}$ \\
\hline Protein $(\mu \mathrm{g} / \mathrm{ml}$ ELF) & $69 \pm 22$ & $49 \pm 20$ & $71.6 \pm 20$ & $76 \pm 18$ & $43 \pm 13$ & $84 \pm 30$ \\
\hline $\operatorname{ELF}(m L)$ & $1.1 \pm 0.2$ & $1.7 \pm 0.3$ & $1.5 \pm 0.3$ & $1.1 \pm 0.1$ & $1.6 \pm 0.3$ & $1.4 \pm 0.5$ \\
\hline Total viable cells $\left(\times 10^{6}\right)$ & $6.8 \pm 2.0$ & $6.2 \pm 2.0$ & $6.6 \pm 1.5$ & $6.0 \pm 1.0$ & $6.0 \pm 2.0$ & $6.6 \pm 1.0$ \\
\hline Percent alveolar & & & & & & \\
\hline macrophages & $96 \pm 1$ & $97 \pm 1$ & $89 \pm 4$ & $96 \pm 1$ & $96 \pm 1$ & $75 \pm 6^{\mathrm{A}}$ \\
\hline Percent lymphocytes & $3 \pm 1$ & $2 \pm 1$ & $5 \pm 2$ & $3.3 \pm 1$ & $2.6 \pm 1$ & $4 \pm 1$ \\
\hline Percent neutrophils & $0.8 \pm 0.5$ & $0.4 \pm 0.2$ & $5.8 \pm 3.5$ & $0.7 \pm 0.5$ & $1.4 \pm 1$ & $5.4 \pm 2$ \\
\hline Percent eosinophils & $0.2 \pm 0.2$ & $0 \pm 0$ & $0.3 \pm 0.3$ & $0.1 \pm 0.2$ & $0.1 \pm 0.2$ & $16 \pm 6^{\mathrm{B}}$ \\
\hline
\end{tabular}

BAL specimens from subjects were obtained at baseline and after exposure to allergen for either 10 minutes or 48 hours as described in Methods. Cells were removed by centrifugation, counted (total viable cells) and examined by light microscopy for determining differentials. The concentration of proteins present in the ELF was determined by correcting protein concentration obtained in BAL supernatants by the dilution factor calculated from the ratio of urea concentrations determined in paired samples of BAL and plasma from each subject. Numbers in parentheses represent the number of samples analyzed under each column heading. Specimens examined in this study were obtained from a separate clinical investigation (35). Some of the data on total cell count and differentials for the samples examined were obtained from the previously reported study $(35) .{ }^{A} P=0.012$ for comparison versus baseline control asthmatic. ${ }^{B} P=$ 0.036 for comparison versus baseline control asthmatic, and $P=0.031$ for comparison versus 48 -hour challenge, nonasthmatics. 
removal of cells) were analyzed by stable isotope dilution GC/MS analysis. Typical GC/MS chromatograms obtained using selected ion monitoring for specific fragment ions derived from derivatized 3-bromotyrosine (mass-to-charge ratio $[\mathrm{m} / z] 445$ ) and a synthetic heavy isotope-labeled internal standard, 3Br- $\left[{ }^{13} \mathrm{C}_{6}\right]$ tyrosine $(m / z 451)$, are illustrated in Figure 3 , e and $\mathrm{f}$. Ions with the appropriate $m / z$ and retention time for 3-bromotyrosine were readily observed in BAL recovered from lung segments of asthmatic subjects 48 hours after allergen challenge, but not normal saline challenge. Thus, brominating oxidants are formed after antigen-exposure in the airways of allergic asthmatic individuals.

The content of 3-bromotyrosine present in BAL proteins recovered at baseline ( $t=0$ hours) and after segmental allergen challenge (10 minutes and 48 hours) in both nonasthmatic controls and asthmatic subjects are shown in Figure 4. At baseline, levels of 3-bromotyrosine in BAL proteins from mild allergic asthmatic individuals showed a tendency toward being modestly elevated over those observed in healthy control subjects;

\section{Figure 3}

Effect of localized allergen challenge on allergic asthmatic airway and BAL proteins. An allergic asthmatic subject underwent fiberoptic bronchoscopy and ragweed allergen was instilled into a specific segment of one lung. A segment in the contralateral lung was similarly challenged with normal saline. Forty-eight hours later, fiberoptic bronchoscopy was repeated and both allergenand normal saline-challenged lung segments were lavaged with normal saline and biopsied. ( $\mathbf{a}$ and $\mathbf{b}$ ) Hematoxylin and eosin staining of (a) normal saline- and (b) allergen-challenged lung segments reveals intense leukocyte infiltration and red granular debris from eosinophils in the allergen-challenged segment. High-power magnification view (data not shown) demonstrated that the majority of leukocytes recruited to the allergen-challenged airways were eosinophils. (c and d) Histological analysis of (c) normal saline- and (d) allergen-challenged lung segments by in situ fluorescence microscopy under conditions specific for the heme moiety of EPO reveals intense fluorescence signal in the allergen-challenged segment. (e and $\mathbf{f}$ ) Protein recovered in BAL fluid from (e) normal saline- and (f) allergen-challenged lung segments of an asthmatic subject were analyzed by stable isotope dilution GC-MS for the presence of 3-bromotyrosine $(\mathrm{BrY})$ using selected ion monitoring mode. The chromatograms shown were monitored at $\mathrm{m} / \mathrm{z}$ 445 , the base ion for the $n$-propyl, per pentafluoroproprionyl derivative of 3-bromotyrosine (Figure 1c), as well as the corresponding isotopically enriched counterpart at $\mathrm{m} / \mathrm{z} 451$ derived from the internal standard, 3 -bromo $\left[{ }^{13} C_{6}\right]$ tyrosine. however, the difference failed to reach statistical significance $(116 \pm 84$ vs. $47 \pm 79 \mu \mathrm{mol} / \mathrm{mol}$ tyrosine, baseline asthmatic versus control, respectively; mean $\pm \mathrm{SD}$, $P=0.084 ; n=$ six individuals per group). Immediately after allergen exposure (10 minutes), no significant formation of 3-bromotyrosine was observed in BAL proteins recovered from either nonasthmatic or asthmatic subjects (Figure 4). In contrast, a dramatic increase in protein modification by brominating oxidants was observed in asthmatic subjects 48 hours after allergen exposure $(1,085 \pm 365$ vs. $32 \pm 42 \mu \mathrm{mol} / \mathrm{mol}$ tyrosine; 48 hours after allergen asthmatic versus control, respectively; mean $\pm \mathrm{SD}, P=0.0003$; $n=$ six individuals per group) (Figure 4).

Allergen challenge elicits primarily an eosinophilic response in tissues; however, the content of neutrophils in BAL and endobronchial tissues also rose modestly, though at comparable levels in nonasthmatic and asthmatic subjects (Table 1). Because the concentration of halides in bronchial tissues is not known, and neutrophils can generate low levels of brominating oxidants at plasma levels of halides (Figure 2), we could not
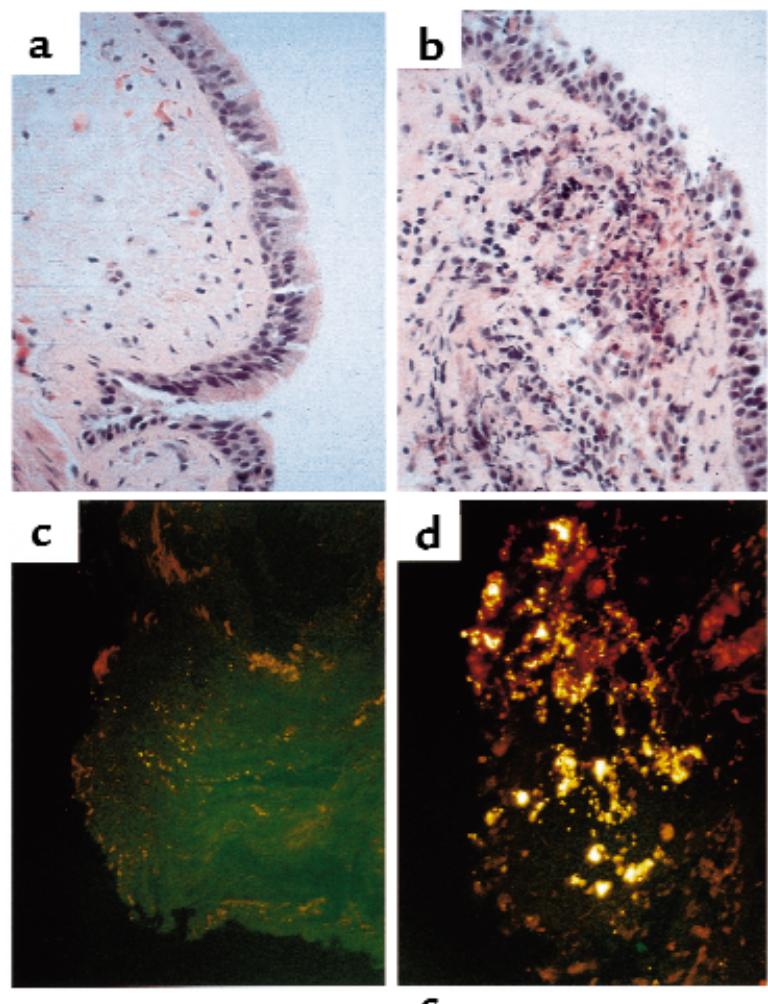

e
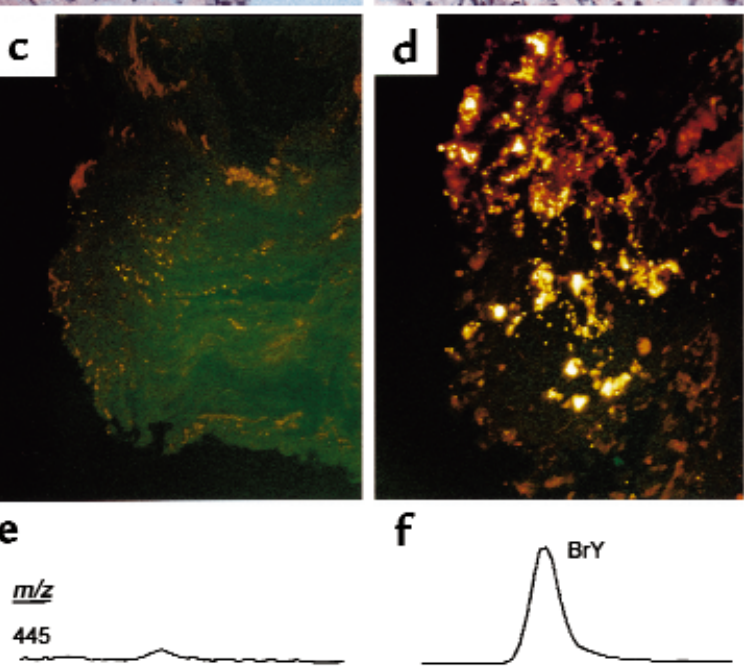

f
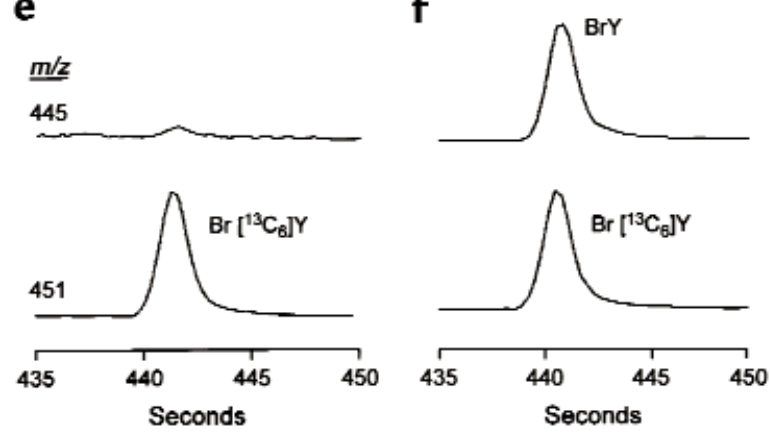


\section{Figure 4}

Quantification of 3-bromotyrosine content in proteins recovered from nonasthmatic and asthmatic subjects at baseline and after segmental allergen challenge. Healthy control and allergic asthmatic subjects underwent fiberoptic bronchoscopy, and a specific segment of one lung was lavaged with normal saline to obtain a baseline sample ( $t=0$ hours). Two specific segments in the contralateral lung were then each exposed to allergen. One of these was lavaged 10 minutes later with normal saline (10 minutes) to assess the immediate effect of allergen challenge. Forty-eight hours later, fiberoptic bronchoscopy was repeated and the other allergen-challenged lung segment was lavaged with normal saline ( 48 hours). Cells in the BAL were removed by centrifugation, and the content of 3-bromotyrosine on proteins recovered in the supernatant at baseline and after segmental allergen challenge was then determined by stable isotope dilution GC/MS. $P$ values represent the comparison between $t=0$ versus 48 hours for allergen-challenged lung segments in asthmatic subjects ( $n=$ six per group).

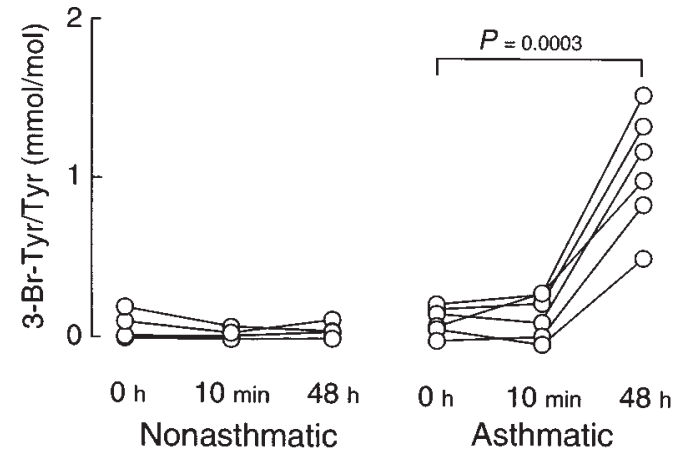

of posttranslational modification of proteins at sites of eosinophil recruitment and activation in humans.

The physiological consequences of EPO-dependent formation of brominating oxidants such as $\mathrm{HOBr}$ in vivo are unknown. $\mathrm{HOBr}$ reacts rapidly with a variety of nucleophilic targets present in biologic matrices such as thiols, thiol ethers, amines, unsaturated groups, and aromatic compounds $(33,55,56)$. Thus, EPO-dependent formation of $\mathrm{HOBr}$ from resident eosinophils may directly contribute to both the rapid loss of reduced glutathione and the rapid inactivation of superoxide dismutase activity observed during antigen-induced asthmatic responses in humans (57). In addition, interaction of $\mathrm{HOBr}$ with targets such as amino acids and $\mathrm{H}_{2} \mathrm{O}_{2}$ can generate secondary reactive species such as $\mathrm{N}$-bromoamines $(55,56)$, aldehydes $(58)$, and singlet oxygen $(59,60)$ that may likewise contribute to events in allergic

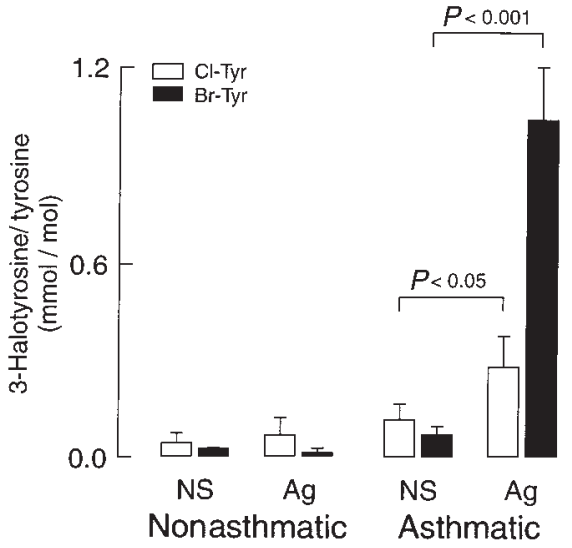

Figure 5

Comparison of protein modification by brominating versus chlorinating oxidants in proteins recovered 48 hours after segmental allergen-challenge. The contents of 3-bromotyrosine and 3-chlorotyrosine generated on proteins in BAL fluid recovered from normal saline (NS) and allergen-challenged (Ag) lung segments (48 hours after challenge) of nonasthmatic and asthmatic subjects were determined by stable isotope dilution GC/MS. Data represent the mean \pm SD ( $n$ = six for each group). Exposure to allergen only caused significant increases in bromination and chlorination of proteins recovered from asthmatic subjects. $n=$ six per group. 
responses. In vitro studies demonstrate that the EPO$\mathrm{H}_{2} \mathrm{O}_{2}-\mathrm{Br}^{-}$system possesses potent antibacteriacidal, fungicidal, -parasitic, and -viricidal activities $(1,11,12$, $14,15,20)$. However, the potential beneficial aspects of these activities within the setting of an allergen-triggered asthma exacerbation are less clear. This is particularly true given the known toxicity of $\mathrm{HOBr}$ and the EPO$\mathrm{H}_{2} \mathrm{O}_{2}-\mathrm{Br}^{-}$system to eukaryotic cells in culture $(4,16)$, and their capacity to elicit many of the pathophysiological features of asthma, including epithelial cell damage and sloughing, airway hyperreactivity, bronchoconstriction, $\beta$-adrenergic dysfunction, mucus hypersecretion, microvascular leak, and edema (61-66).

Similarly, the consequences of tyrosine bromination in vivo are unknown. One obvious potential function might be the modulation of tyrosine kinase- or phosphatase-dependent signaling. Alternatively, it is tempting to speculate that EPO-dependent bromination of tyrosine residues evolved because it may confer an activity that contributes to host defenses. Multiple distinct brominated halometabolites (including brominated tyrosine analogs) possessing antimicrobial activities have been identified in marine organisms such as algae, sponges, bryozoans, tunicates, worms, and molluscs $(48-54,67)$. Synthesis of these halometabolites is thought to be catalyzed by distinct bromoperoxidases that, unlike the hemoprotein EPO, utilize vanadium at their catalytic centers. The high concentrations of halides in seawater has thus apparently been exploited during evolution to promote halogenation of organic molecules as a favored biosynthetic process in these organisms. Whether bromination of targets in mammalian systems confers similar benefits remains to be determined.

The present studies identify EPO as a catalytic source of reactive oxidant species during asthma. They thus suggest EPO as a potential therapeutic target for allergen-triggered inflammatory tissue injury in humans. The ability of halogenated oxidation products in tissues to serve as specific "molecular fingerprints" for proteins damaged by mammalian leukocyte peroxidases should serve as valuable tools in identifying the functions of EPO, MPO, and halogenating oxidants in host defenses and inflammation.

\section{Acknowledgments}

Mass spectrometry experiments were performed at the Lerner Research Institute Mass Spectrometry Facility. This work was supported in part by the American Heart Association and by the National Institutes of Health (grants HL-61878 and HL-62526).

1. Klebanoff, S.J., Locksley, R.M., Jong, E.C., and Rosen, H. 1983. Oxidative response of phagocytes to parasite invasion. Ciba Found. Symp. 99:92-112.

2. Weiss, S.J., Test, S.T., Eckmann, C.M., Ross, D., and Regiania, S. 1986. Brominating oxidants generated by human eosinophils. Science. 234:200-203.

3. Mayeno, A.N., Curran, A.J., Roberts, R.L., and Foote, C.S. 1989. Eosinophils preferentially use bromide to generate halogenating agents. J. Biol. Chem. 264:5660-5668.

4. Agosti, J.M., et al. 1987. The injurious effect of eosinophil peroxidase, hydrogen peroxide, and halides on pneumocytes in vitro. J. Allergy Clin. Immunol 79:496-504.

5. Gleich, G.J., Ottesen, E.A., Leiferman, K.M., and Ackerman, S.J. 1989. Eosinophils and human disease. Int. Arch. Allergy Appl. Immunol. 88:59-62.

6. Rothenberg, M.E. 1998. Eosinophilia. N. Engl. J. Med. 338:1592-1600.

7. Holt, P.G., Macaubas, C., Stumbles, P.A., and Sly, P.D. 1999. The role of allergy in the development of asthma. Nature. 402:B12-B17.

8. DeChatelet, L.R., et al. 1977. Oxidative metabolism of the human eosinophil. Blood. 50:525-535.

9. Slungaard, A., Vercellotti, G.M., Walker, G., Nelson, R.D., and Jacob, H.S. 1990. Tumor necrosis factor alpha/cachectin stimulates eosinophil oxidant production and toxicity towards human endothelium. J. Exp. Med. 171:2025-2041.

10. Someya, A., Nishijima, K., Nunoi, H., Irie, S., and Nagaoka, I. 1997. Study on the superoxide-producing enzyme of eosinophils and neutrophils-comparison of the NADPH oxidase components. Arch. Biochem. Biophys. 345:207-213.

11.Jong, E.C., Henderson, W.R., and Klebanoff, S.J. 1980. Bactericidal activity of eosinophil peroxidase. J. Immunol. 124:1378-1382.

12. Jong, E.C., Mahmoud, A.A., and Klebanoff, S.J. 1981. Peroxidase-mediated toxicity to schistosomula of Schistosoma mansoni. J. Immunol. 126:468-471.

13. Slungaard, A., and Mahoney, J.R., Jr. 1991. Bromide-dependent toxicity of eosinophil peroxidase for endothelium and isolated working rat hearts: a model for eosinophilic endocarditis. J. Exp. Med. 173:117-126.

14. Klebanoff, S.J., Agosti, J.M., Jorg, A., and Waltersdorph, A.M. 1989. Comparative toxicity of the horse eosinophil peroxidase-H2O2-halide system and granule basic proteins. J. Immunol. 143:239-244.

15. Kazura, J.W., Fanning, M.M., Blumer, J.L., and Mahmoud, A.A. 1981. Role of cell-generated hydrogen peroxide in granulocyte-mediated killing of schistosomula of Schistosoma mansoni in vitro. J. Clin. Invest. 67:93-102.

16. Samoszuk, M.K., Nguyen, V., Thomas, C., and Jacobson, D. 1994. Effects of sonicated eosinophils on the in vivo sensitivity of human lymphoma cells to glucose oxidase. Cancer Res. 54:2650-2653.

17. Carlson, M.G., Peterson, C.G., and Venge, P. 1985. Human eosinophil peroxidase: purification and characterization. J. Immunol. 134:1875-1879.

18. Ten, R.M., Pease, L.R., McKean, D.J., Bell, M.P., and Gleich, G.J. 1989. Molecular cloning of the human eosinophil peroxidase. Evidence for the existence of a peroxidase multigene family. J. Exp. Med. 169:1757-1769.

19. Sakamaki, K., Tomonaga, M., Tsukui, K., and Nagata, S. 1989. Molecular cloning and characterization of a chromosomal gene for human eosinophil peroxidase. J. Biol. Chem. 264:16828-16836.

20. Jong, E.C., and Klebanoff, S.J. 1980. Eosinophil-mediated mammalian tumor cell cytotoxicity: role of the peroxidase system. J. Immunol. 124:1949-1953

21. Weiss, S.J., Klein, R., Slivka, A., and Wei, M. 1982. Chlorination of taurine by human neutrophils. Evidence for hypochlorous acid generation. J. Clin. Invest. 70:598-607.

22. Foote, C.S., Goyne, T.E., and Lehrer, R.I. 1983. Assessment of chlorination by human neutrophils. Nature. 301:715-716.

23. Hazen, S.L., Hsu, F.F., Mueller, D.M., Crowley, J.R., and Heinecke, J.W. 1996. Human neutrophils employ chlorine gas as an oxidant during phagocytosis. J. Clin. Invest. 98:1283-1289.

24. Slungaard, A., and Mahoney, J.R., Jr. 1991. Thiocyanate is the major substrate for eosinophil peroxidase in physiologic fluids. Implications for cytotoxicity. J. Biol. Chem. 266:4903-4910.

25. Teitz, N.W. 1999. Drugs: therapeutic and toxic. In Teitz textbook of clinical chemistry. C.A. Burtis and E.R. Ashwood, editors. W.B. Saunders Co. Philadelphia, Pennsylvania, USA. p. 2216.

26. Hazen, S.L., Hsu, F.F., and Heinecke, J.W. 1996. p-Hydroxyphenylacetaldehyde is the major product of L-tyrosine oxidation by activated human phagocytes: a chloride-dependent mechanism for the conversion of free amino acids into reactive aldehydes by myeloperoxidase. $J$. Biol. Chem. 271:1861-1867.

27. Thurau, A.M., Schylz, U., Wolf, V., Krug, N., and Schauer, U. 1996. Identification of eosinophils by flow cytometry. Cytometry. 23:150-158.

28. Hansel, T.T., et al. 1989. Purification of human blood eosinophils by negative selection using immunomagnetic beads. J. Immunol. Methods. 122:97-103

29. van Dalen, C.J., Whitehouse, M.W., Winterbourn, C.C., and Kettle, A.J. 1997. Thiocyanate and chloride as competing substrates for myeloperoxidase. Biochem. J. 327:487-492.

30. Babior, B.M., Kipnes, R.S., and Curnutte, J.T. 1973. Biological defense mechanism: the production by leukocytes of superoxide, a potential bactericidal agent. J. Clin. Invest. 52:741-744.

31. Hazen, S.L., Crowley, J.R., Mueller, D.M., and Heinecke, J.W. 1997. Mass spectrometric quantification of 3-chlorotyrosine in human tissues with attomole sensitivity: a sensitive and specific marker for myeloper- 
oxidase-catalyzed chlorination at sites of inflammation. Free Radic. Biol. Med. 23:909-916.

32. Hazen, S.L., and Heinecke, J.W. 1997. 3-Chlorotyrosine, a specific marker of myeloperoxidase-catalyzed oxidation, is markedly elevated in low density lipoprotein isolated from human atherosclerotic intima. J. Clin. Invest. 99:2075-2081.

33. Wu, W., Chen, Y., d'Avignon, A., and Hazen, S.L. 1999. 3-Bromotyrosine and 3,5-dibromotyrosine are major products of protein oxidation by eosinophil peroxidase: potential markers for eosinophil-dependent tissue injury in vivo. Biochemistry. 38:3538-3548.

34. Heinecke, J.W., et al. 1999. Detecting oxidative modification of biomolecules with isotope dilution mass spectrometry: sensitive and quantitative assays for oxidized amino acids in proteins and tissues. Methods Enzymol. 300:124-144.

35. Thomassen, M.J., et al. 1999. Nitric oxide regulation of asthmatic airway inflammation with segmental allergen challenge. J. Allergy Clin. Immunol. 104:1174-1182.

36. National Heart, Lung, and Blood Institute. 1997. Expert panel report 2: guidelines for the diagnosis and management of asthma. National Institutes of Health. Bethesda, Maryland, USA. Publication no. 97. 4051. pp. $1-86$.

37. Hazen, S.L., Hsu, F.F., Gaut, J.P., Crowley, J.R., and Heinecke, J.W. 1999. Modification of proteins and lipids by myeloperoxidase-derived oxidants. Methods Enzymol. 300:88-105.

38. Fuerst, D.E., and Jannach, J.R. 1965. Autofluorescence of eosinophils: a bone marrow study. Nature. 205:1333-1335.

39. Weil, G.J., and Chused, T.M. 1981. Eosinophil autofluorescence and its use in isolation and analysis of human eosinophils using flow microfluorometry. Blood. 57:1099-1104.

40. Samoszuk, M.K., and Espinoza, F.P. 1987. Deposition of autofluorescent eosinophil granules in pathologic bone marrow biopsies. Blood. 70:597-599.

41. Bos, A.J., Wever, R., Hamers, M.N., and Roos, D. 1981. Some enzymatic characteristics of eosinophil peroxidase from patients with eosinophilia and from healthy donors. Infect. Immun. 32:427-431.

42. Samoszuk, M.K., Lukes, R.J., and Nathwani, B. 1986. Extensive deposition of eosinophil peroxidase in Hodgkin's and non-Hodgkin's lymphomas. Am. J. Pathol. 125:426-429.

43. Sedgwick, J.B., et al. 1992. Comparison of airway and blood eosinophil function after in vivo antigen challenge. J. Immunol. 149:3710-3718.

44. Smith, H.R., et al. 1992. Inflammatory cells and eicosanoid mediators in subjects with late asthmatic responses and increases in airway responsiveness. J. Allergy Clin. Immunol. 89:1076-1084.

45. Sanders, S.P., et al. 1995. Spontaneous oxygen radical production at sites of antigen challenge in allergic subjects. Am. J. Respir. Crit. Care Med. 151:1725-1733.

46. Jarjour, N.N., et al. 1997. The immediate and late allergic response to segmental bronchopulmonary provocation in asthma. Am. J. Respir. Crit. Care Med. 155:1515-1521.

47. Teitz, N.W. 1999. Drugs: therapeutic and toxic. In Teitz textbook of clinical chemistry. C.A. Burtis and E.R. Ashwood, editors. W.B. Saunders Co. Philadelphia, Pennsylvania, USA. p. 1097.

48. Faulkner, D.J. 1998. Marine natural products. Nat. Prod. Rep. 15:113-158.

49. James, D.M., Kunze, H.B., and Faulkner, D.J. 1991. Two new brominated tyrosine derivatives from the sponge Druinella (Psammaplysilla) purpurea. J. Nat. Prod. 54:1137-1140.
50. Manthey, J.A., Hager, L.P., and McElvany, K.D. 1984. Protein bromination by bromoperoxidase from Penicillus capitatus. Methods Enzymol. 107:439-445.

51. Beissner, R.S., Guilford, W.J., Coates, R.M., and Hager, L.P. 1981. Synthesis of brominated heptanones and bromoform by a bromoperoxidase of marine origin. Biochemistry. 20:3724-3731.

52. Carney, J.R., and Rinehart, K.L. 1995. Biosynthesis of brominated tyrosine metabolites by Aplysina fistularis. J. Nat. Prod. 58:971-985.

53. Mierezwa, R., et al. 1994. Verongamine, a novel bromotyrosine-derived histamine $\mathrm{H}_{3}$-antagonist from the marine sponge Verongula gigantea. J. Nat. Prod. 57:175-177.

54. Gunasekera, S.P., and Cross, S.S. 1992. Fistularin 3 and 11-ketofistularin 3. Feline leukemia virus active bromotyrosine metabolites from the marine sponge Aplysina archeri. J. Nat. Prod. 55:509-512.

55. Wajon, J.E., and Morris, J.C. 1980. Bromination chemistry: rates of formation of $\mathrm{NH}_{2} \mathrm{Br}$ and some $\mathrm{N}$-brominated amino acids. In Water chlorination: environmental impact and health effects. R.L. Jolley, W.A. Brungs, R.B. Cumming, and V.A. Jacobs, editors. Ann Arbor Science Publishers Inc. Ann Arbor, Michigan, USA. 171-181.

56. Thomas, E.L., Bozeman, P.M., Jefferson, M.M., and King, C.C. 1995. Oxidation of bromide by the human leukocyte enzymes myeloperoxidase and eosinophil peroxidase. Formation of bromamines. J. Biol. Chem. 270:2906-2913.

57. Comhair, S.A., Bhathena, P., Dweik, R.A., Kavuru, M.S., and Erzurum, S.C. 2000. Rapid loss of superoxide dismutase activity during antigeninduced asthmatic response. Lancet. 355:624.

58. Hazen, S.L., d'Avignon, A., Anderson, M.M., Hsu, F.F., and Heinecke, J.W. 1998. Human neutrophils employ the myeloperoxidase-hydrogen peroxide-chloride system to oxidize alpha-amino acids to a family of reactive aldehydes. Mechanistic studies identifying labile intermediates along the reaction pathway. J. Biol. Chem. 273:4997-5005.

59. Kanofsky, J.R., Hoogland, H., Wever, R., and Weiss, S.J. 1988. Singlet oxygen production by human eosinophils. J. Biol. Chem. 263:9692-9696.

60. Kanofsky, J.R. 1989. Bromine derivatives of amino acids as intermediates in the peroxidase-catalyzed formation of singlet oxygen. Arch. Biochem. Biophys. 274:229-234.

61. Brottman, G.M., Regelmann, W.E., Slungaard, A., and Wangensteen, O.D. 1996. Effect of eosinophil peroxidase on airway epithelial permeability in the guinea pig. Pediatr. Pulmonol. 21:159-166.

62. Yoshikawa, S., Kayes, S.G., and Parker, J.C. 1993. Eosinophils increase lung microvascular permeability via the peroxidase-hydrogen peroxidehalide system. Bronchoconstriction and vasoconstriction unaffected by eosinophil peroxidase inhibition. Am. Rev. Respir. Dis. 147:914-920.

63. Pretolani, M., et al. 1994. Role of eosinophil activation in the bronchial reactivity of allergic guinea pigs. Am. J. Respir. Crit. Care Med. 149:1167-1174.

64. Hamann, K.J., et al. 1993. Effects of activated eosinophils cultured from human umbilical cord blood on guinea pig trachealis. Am. J. Physiol. 265:L301-L307.

65. Minnicozzi, M., Duran, W.N., Gleich, G.J., and Egan, R.W. 1994. Eosinophil granule proteins increase microvascular macromolecular transport in the hamster cheek pouch. J. Immunol. 153:2664-2670.

66. Gundel, R.H., Letts, L.G., and Gleich, G.J. 1991. Human eosinophil major basic protein induces airway constriction and airway hyperresponsiveness in primates. J. Clin. Invest. 87:1470-1473.

67. McCord, T.J., et al. 1975. Synthesis and microbiological activities of some monohalogenated analogs of tyrosine. J. Med. Chem. 18:26-29. 